\title{
ANÁLISE TEMÁTICA DIALÓGICA APLICADA A UMA RODA DE CONVERSA COM CRIANÇAS: uma explanação baseada em relato de pesquisa
}

\author{
Larissa Krüger-Fernandes \\ Lady Daiane Martins Ribeiro \\ Fabricia Teixeira Borges
}

Resumo

Este artigo tem o objetivo de apresentar a Análise Temática Dialógica, seus fundamentos epistemológicos e sua aplicação em um contexto de pesquisa qualitativa com crianças. Partindo da concepção de linguagem elaborada e desenvolvida pelo Círculo de Bakhtin, apresentam-se os pressupostos que embasam esse tipo de análise: o caráter dialógico da língua, o entendimento da palavra como signo ideológico e a concepção de tema. São abordados também os conceitos de endereçamento e alteridade que guiam as análises, de modo que todo enunciado do(a) participante é considerado em relação ao outro - ou aos outros - a quem ele(a) se dirige. Após essa explanação inicial, apresenta-se um relato prático da aplicação da Análise Temática Dialógica às informações produzidas em uma pesquisa sobre tecnologia com crianças. A pesquisa se utilizou de roda de conversa como procedimento metodológico para investigar os significados presentes nas falas das crianças participantes sobre a presença das tecnologias em suas vidas.

Palavras-chave: análise temática dialógica; roda de conversa; crianças.

\section{DIALOGICAL THEMATIC ANALYSIS APPLIED TO A CONVERSATION CIRCLE WITH CHILDREN:} an explanation based on a research report

\begin{abstract}
This article aims to present the Dialogical Thematic Analysis, its epistemological foundations and its application to a context of qualitative research with children. Based on the conception of language developed by the Bakhtin Circle, we present the theoretical foundations that support this type of analysis, which include: the dialogical character of language, the understanding of words as ideological signs and the concept of theme. Other concepts are also discussed, such as utterance addressing and otherness, which guide the analysis in such a way that every statement of the participant is considered in relation to the other - or to the others - to whom he/she addresses. After an initial explanation, we present a practical application of the Dialogical Thematic Analysis to the information produced in a research with children about the presence of technologies in their lives. The conversation circle was adopted as a methodological procedure in order to produce the information with the children.
\end{abstract}

Keywords: dialogical thematic analysis; conversation circle; children. 


\section{ANÁLISIS TEMÁTICO DIALÓGICO APLICADO A UN CÍRCULO DE CONVERSACIÓN: una explicación basada en relato de investigación}

\section{Resumen}

Este artículo tiene como objetivo presentar el Análisis Temático Dialógico, sus fundamentos epistemológicos y su aplicación en un contexto de investigación cualitativa con niños. Partiendo de la concepción del lenguaje elaborada y desarrollada por el Círculo de Bajtín, presentamos los supuestos que respaldan este tipo de análisis: el carácter dialógico del lenguaje, la comprensión de la palabra como signo ideológico y el concepto de tema. También se abordan otros conceptos relevantes como el direccionamiento del enunciado y la alteridad; cuestiones que guían nuestro análisis de tal manera que cada declaración de un participante se considera en relación al otro - o a los otros - a quien se dirige. Después de esta explicación inicial, se presenta un ejemplo práctico de la aplicación del Análisis Temático Dialógico a la información producida en una investigación sobre el uso de tecnología por parte de niños. La investigación utilizó un círculo de conversación como procedimiento metodológico para abordar los significados presentes en los discursos de los niños; particularmente en lo que tenía que ver con la presencia de las tecnologías en sus vidas.

Palabras-clave: análisis temático dialógico; círculo de conversación; niños.

\section{INTRODUÇÃO}

Este artigo pretende apresentar os fundamentos epistemológicos da Análise Temática Dialógica e demonstrar sua aplicabilidade em um contexto de pesquisa com crianças no qual se utilizou da roda de conversa como procedimento metodológico. Ancorada na filosofia da linguagem do Círculo de Bakhtin, a Análise Temática Dialógica nos convida a refletir e problematizar as condições materiais da interação dialógica, enfatizando as características do jogo interlocucional que se estabelece entre os falantes. Por esse motivo, caracteriza-se como um método de análise de informações produzidas em contextos de interação dialógica como entrevistas (individuais ou em grupo), grupos focais e rodas de conversa - caso tratado neste artigo.

A Análise Temática Dialógica se configura como um procedimento de análise qualitativa e vem sendo utilizado principalmente para tratamento de informações em pesquisas conduzidas na área da Psicologia do Desenvolvimento (BERALDO, 2017; BORGES, 2006; CAIXETA, 2006; KRÜGER-FERNANDES, 2018; NAVES, 2019; PAIXÃO, 2020; SILVA; BORGES, 2017). Por enfatizar aspectos relacionados à linguagem e à alteridade no processo de interação dialógica, esse tipo de análise se mostra como um instrumento profícuo para analisar as informações produzidas no contexto da pesquisa em Psicologia do Desenvolvimento, apoiada principalmente nos pressupostos da Psicologia Cultural.

De acordo com as teorias em psicologia cultural, o desenvolvimento humano ocorre em um processo histórico entre um sujeito ativo e reflexivo e seu ambiente cultural (VALSINER; ROSA, 2007; VIGOTSKI, 2010). Por isso, um ponto-chave dessa perspectiva é a interação com o outro e com os artefatos culturais. Essas interações são sempre mediadas pela linguagem, ou seja, encontram-se sempre marcadas pela mediação semiótica (BRUNER, 1997; VALSINER; ROSA, 2007; WERTSCH, 1994). Os instrumentos e símbolos culturais que estão presentes nas interações entre os sujeitos e entre o sujeito e o mundo são, ao mesmo tempo, produtos da cultura e mediadores da cultura, tendo dois componentes: um material e outro simbólico 
(VIGOTSKI, 2010). São esses componentes que caracterizam as funções psicológicas superiores como funções culturais e participam da constituição dos indivíduos como seres humanos (VYGOTSKI, 2014; VIGOTSKI; LEONTIEV; LURIA, 2016).

Para Bakhtin (2011), a consciência só é possível na relação com o outro por meio da linguagem, a qual acaba por constituir-se como material da consciência. Os signos funcionam como instrumentos que medeiam a relação dos sujeitos com a realidade, atuando em conjunto com as impressões, as quais também assumem um caráter significativo pela linguagem. O signo é social e produto da atividade humana, sempre emergente das interlocuções que ocorrem em espaço interindividual; isso caracteriza a consciência como fato socioideológico, sendo impossível entendê-la ou analisá-la fora de seu contexto cultural (BAKHTIN, 2011).

Portanto, para a compreensão do desenvolvimento humano na perspectiva da Psicologia Cultural, a linguagem assume um papel crucial, assim como para a filosofia desenvolvida no âmbito do Círculo de Bakhtin. Por isso, ao abordarmos as informações construídas em pesquisa, é necessário que estejamos atentos à reconstituição das condições em que os enunciados foram proferidos, o que possibilitará uma análise em que as múltiplas possibilidades de sentido sejam consideradas, assim como os movimentos de endereçamento e alteridade que se fazem presentes no momento da interação.

A Análise Temática Dialógica parte das ideias elaboradas por Mikhail Bakhtin e seu Círculo a respeito da linguagem para analisar as interações dialógicas entre participantes e entre participantes e pesquisador(a). Como pressupostos desse tipo de análise, abordamos: a concepção de tema apresentada no livro Marxismo e Filosofia da Linguagem (VOLÓCHINOV, 2017¹), o caráter dialógico da língua e o entendimento da palavra como signo ideológico, assim como as noções de alteridade e endereçamento, ressaltadas pelos autores, nos contextos reais de utilização da língua.

Nas seções seguintes esses pressupostos serão apresentados de forma mais elaborada, e em seguida, um exemplo de aplicabilidade da análise será descrito a partir de uma pesquisa conduzida com crianças que se utilizou de roda de conversa como procedimento metodológico para investigar os significados presentes nas falas das crianças quanto à presença das tecnologias em suas vidas. A análise apresentada neste artigo foi assim conduzida, buscando-se contemplar esses movimentos e articular as vozes das crianças - autoras de suas palavras - com o contexto dialógico em que foram proferidas, ou seja, articulando-se o texto com o contexto dialógico de seu tempo.

\section{Fundamentos epistemológicos da Análise Temática Dialógica}

A linguagem em Bakhtin se configura pela manifestação concreta da realidade social no entendimento do sujeito em relação aos processos enunciativos. Segundo Bakhtin, “[...] nenhuma enunciação verbalizada pode ser atribuída exclusivamente a quem a enunciou: é produto da interação entre falantes" (2001, p. 79). Em termos gerais, é fruto da situação social na qual foi gerada. Desse modo, o autor enfatiza a importância da interação verbal do sujeito com outros sujeitos para a constituição de si: o outro direciona o sujeito e a constituição de sua identidade, pois é no meio social que o sujeito adquire sua linguagem tendo nela suas significações e apreciações. É por meio do outro que nos constituímos e também por meio dele que

\footnotetext{
${ }^{1}$ Optamos pela tradução de Marxismo e Filosofia da Linguagem publicada em 2017 pela editora 34, que atribui a autoria do texto a Valentin Volóchinov, por se tratar de uma edição mais atual, vertida diretamente do russo para o português pelas autoras Sheila Grillo e Ekaterina Vólkova Américo.
} 
descobrimos quem somos, ou seja, o outro é o espelho que reflete (e refrata) o sujeito; então, somos também o outro (PONZIO, 2012). A partir disso, "[...] ao tomar consciência de mim mesmo, eu tento como que olhar para mim pelos olhos de outra pessoa, de outro representante do meu grupo social, da minha classe" (BAKHTIN, 2001, p. 87). Os sujeitos são sempre sociais em constante alteridade, já que cada sujeito se constitui na relação com o outro, ou seja, o sujeito é dialógico. Dessa forma, a relação eu-tu, que surge do aparato dialógico, deve ser entendida a partir da concepção de um sujeito que é atravessado por diversas vozes sociais, fazendo desse sujeito um sujeito histórico e ideológico.

$\mathrm{Na}$ interação verbal, na qual podemos entender a gênese da formação do eu e de suas vozes, Bakhtin (2011) define três categorias: o eu para mim, o eu para os outros e o outro para mim. O "eu para mim" refere-se à autopercepção; o "eu para os outros", ao que eu pareço aos olhos dos outros, e "o outro para mim" a como eu percebo o outro. Daí deriva o conceito de exotopia, uma posição externa que me permite ver o outro em sua totalidade, sua imagem e expressão, inacessíveis a ele próprio. Enquanto isso, o outro vê o que eu não posso ver, caracterizando a relação eu-outro como complementar e sendo essa a base para o processo dialógico em Bakhtin (AMORIM, 2012). A língua, nessa perspectiva de trabalho, apresenta-se como a ponte que interliga os sujeitos e os define atuando em sua constituição como sujeitos históricos e sociais (BAKHTIN, 2011; VOLÓCHINOV, 2017). Essa relação de comunicação leva o sujeito a produzir dizeres na espera de uma resposta, seja ela de concordância, protesto, objeção ou problematização. Assim, o sujeito bakhtiniano é gerador de respostas, posiciona-se.

Ao posicionarem-se, os sujeitos enunciam a partir do processo sócio-histórico em que se encontram inscritos e é nesse processo que se dá a construção ideológica das palavras. Consequentemente, a palavra é o signo ideológico por excelência, o único signo que tem a possibilidade de assumir qualquer função ideológica, seja ela estética, científica, moral ou religiosa (VOLÓCHINOV, 2017). Nesse sentido, a palavra é considerada um signo neutro, podendo ser utilizada em diferentes contextos sociais, enquanto os outros objetos adquirem simbolismo em um domínio específico. Além disso, a palavra, nessa perspectiva, se configura como o indicador mais sensível das mudanças ideológicas, capaz de registrar as transformações sociais mais transitórias e efêmeras no cerne da sociedade (VOLÓCHINOV, 2017).

O conceito de significação é explorado e elaborado teoricamente ao longo do livro Marxismo e Filosofia da Linguagem de Volóchinov (2017) e se refere de maneira geral à capacidade de significar do signo. Para a Análise Temática Dialógica, o interesse recai mais aprofundadamente nas relações dos processos de significação com a concepção de tema explorada no capítulo Tema e Significação da Língua do livro já citado. Nessa perspectiva, não existe tema sem significação, apontando a impossibilidade de estabelecer um limite absoluto entre tema e significação (VOLÓCHINOV, 2017). A significação pode ser considerada um estágio mais estável dos signos e dos enunciados referindo-se aos elementos que são reiteráveis e decorrentes de um processo de convenção. O tema, por sua vez, refere-se à situação histórica concreta na qual o enunciado foi gerado, ou seja, o tema é irrepetível, único e compreende tanto os elementos estáveis da significação, como também os elementos extraverbais presentes na situação de produção, recepção e circulação dos enunciados (VOLÓCHINOV, 2017; CEREJA, 2005). Nesse sentido, o tema do enunciado compreende suas formas linguísticas - palavras, sons, entonação - e também os aspectos extraverbais da situação, sem os quais "[...] o enunciado torna-se incompreensível, assim como aconteceria se ele estivesse desprovido de suas palavras mais importantes" (VOLÓCHINOV, 2017, p. 228). 
Por conseguinte, considera-se que o tema do enunciado é tão concreto quanto o movimento histórico ao qual ele pertence, e que o enunciado só possuirá o tema se for considerado um fenômeno histórico em sua plenitude concreta (VOLÓCHINOV, 2017). É dessa forma que o instável e o inusitado do contexto concreto do enunciado se juntam aos processos de significação mais estáveis na construção da concepção de tema. É a consideração desses elementos que caracteriza a especificidade da Análise Temática Dialógica como instrumento de análise.

Em complemento aos conceitos elaborados por Bakhtin e o Círculo, que servem de fundamentação direta da Análise Temática Dialógica, também consideramos o posicionamento de Mikhail Bakhtin em relação às Ciências Humanas. Para Bakhtin e o Círculo, as Ciências Humanas são ciências do texto, pois, em sua concepção, o que define o humano é ser sujeito falante, ou seja, produtor de textos. Nesse sentido, as Ciências Humanas são profundamente marcadas pelo seu caráter dialógico e, justamente por isso, faz-se crucial a reconstituição das condições de enunciação para o momento da análise, permitindo que as múltiplas possibilidades de sentido sejam consideradas e evitando a fusão das vozes presentes na pesquisa (AMORIM, 2002, 2012). A pesquisa que será apresentada nas próximas seções partiu dessas reflexões para desenvolver seu processo de análise, cuidando para que o texto do pesquisador não emudecesse o texto do pesquisado e que tampouco o texto do pesquisado emudecesse o texto do pesquisador, o qual não pode se eximir de trazer de sua posição exterior seus valores e suas teorias, revelando do pesquisado o que nem ele mesmo pode ver (AMORIM, 2012).

\section{METODOLOGIA}

\section{Apresentação da pesquisa}

A partir desse enfoque dialógico (BAKHTIN, 2011), a pesquisa relatada neste artigo foi estruturada em três momentos: 1) Roda de Conversa sobre Tecnologia; 2) Produção de Vídeos sobre Tecnologia pelas Crianças; e 3) Roda de Conversa sobre os Vídeos. Com o intuito de exemplificar a aplicação da Análise Temática Dialógica, selecionamos as informações produzidas durante o primeiro procedimento metodológico: A Roda de Conversa sobre Tecnologia. O objetivo específico desse procedimento foi identificar temas emergentes em roda de conversa com crianças sobre a presença das tecnologias em suas vidas. Os encontros com as crianças ocorreram em uma sala da área comum do condomínio em que elas moravam, o qual se localiza em uma Região Administrativa do Distrito Federal. Participaram da pesquisa quatro crianças com idades variando de 9 a 12 anos, como pode ser observado na Tabela 1.

Tabela 1. Caracterização dos participantes. *Codinomes escolhidos pelas crianças

\begin{tabular}{|c|c|c|}
\hline Codinome & Sexo & Idade \\
\hline Bela & F & 12 \\
\hline Unicórnio & F & 11 \\
\hline Mar & F & 09 \\
\hline Superman & M & 09 \\
\hline
\end{tabular}

Fonte: Elaborada por Krüger-Fernandes, 2018 


\section{APLICAÇÃO DA ANÁLISE TEMÁTICA DIALÓGICA}

Os pressupostos apresentados na primeira parte deste texto guiam todo o processo de aplicação da Análise Temática Dialógica, o qual é marcado pela dinamicidade e flexibilidade envolvendo "[...] um constante ir e vir no material produzido/analisado, evidenciando, uma vez mais, seu caráter dialógico" (SILVA; BORGES, 2017, p. 251). Por isso, ressaltamos que a Análise Temática Dialógica vem sendo aplicada a informações construídas em diferentes contextos de pesquisa, com pequenas variações, e que neste artigo apresentamos a sistematização do processo de análise particular empreendido na pesquisa aqui relatada, a qual foi marcada pela configuração da roda de conversa com crianças.

Foram conduzidas as seguintes etapas: (a) transcrição do material (videogravado); (b) leitura intensiva com o foco no encadeamento dos enunciados; (c) organização dos enunciados ou blocos de enunciados em temas e subtemas; (d) elaboração e análise dos mapas semióticos. A organização gráfica dos resultados em mapas se dá de maneira bastante livre, e seu objetivo é representar visualmente como os temas e subtemas identificados na análise dialogam, relacionamse ou contrapõem-se. Recomenda-se a utilização de formas e cores diferenciadas para destacar temas e subtemas, bem como a utilização de traços ou setas para indicar as relações identificadas entre eles.

No caso da pesquisa aqui apresentada, que se utilizou de roda de conversa em que participaram quatro crianças e a pesquisadora, o jogo interlocucional que se estabeleceu entre esses sujeitos foi caracterizado por um múltiplo endereçamento dos enunciados e em muitas situações se configurou como um raciocínio exteriorizado nos moldes dos que nos apresentam Pontecorvo, Ajello e Zucchermaglio (2005). A aproximação do material audiovisual (de videogravação) e do material transcrito se dá com esse olhar minucioso que prioriza o endereçamento dos enunciados produzidos na interação e o encadeamento dos diálogos, assim como as expressões verbais e corporais que também participam da emergência do tema. Dessa forma, a transcrição levou em consideração as falas literais dos participantes, a descrição do comportamento e aspectos da interação que ocorriam no momento da fala. Para a transcrição, foram adotados os seguintes símbolos: $\mathrm{P}=$ Pesquisadora; $\mathrm{B}=$ Bela; $\mathrm{U}=$ Unicórnio; $\mathrm{M}=$ Mar; $\mathrm{S}=$ Superman;.$=$ pausa curta; ..= pausa média; $\ldots=$ pausa longa; palavra $=$ ênfase; ${ }_{-}=$fala sobreposta; $(. .)=$. inaudibilidade; $[. .]=$. supressão de falas para melhor entendimento do diálogo; $*=$ descrição do comportamento.

O material videogravado foi transcrito de maneira cronológica em relação aos acontecimentos, em blocos de diálogos, os quais já traziam pistas sobre a definição dos temas emergentes. Algumas vezes, os temas foram trazidos pela pesquisadora para a roda de conversa com o objetivo de abordar seu objeto de estudo de maneira mais direta. Outras vezes foram colocados pelos participantes em suas falas e expressões corporais. Da mesma forma, os subtemas relacionados aos temas centrais foram emergindo na interação dialógica entre participantes e pesquisadora.

Os temas e subtemas foram organizados de maneira cronológica em uma tabela (Figura 1) utilizando-se cores para diferenciação e para aproximação desses componentes. Salientamos que a tabela expressa na Figura 1 sofreu várias modificações e pretende refletir o processo de análise em construção, admitindo a presença de falas das crianças relacionadas aos temas e subtemas, assim como anotações da pesquisadora que podem auxiliar análises posteriores. Na Figura 1, pode ser vista a tabela de temas e subtemas organizados em ordem cronológica de emergência ao longo da roda de conversa. 
Figura 1. Tabela de organização de temas e subtemas em ordem cronológica

\begin{tabular}{|c|c|c|c|}
\hline \begin{tabular}{|l|} 
RODA DE \\
CONVERSA SOBRE \\
TECNOLOGIA \\
\end{tabular} & & & \\
\hline \multirow[t]{4}{*}{ ROTINAS } & \multicolumn{3}{|l|}{ ESCOLA } \\
\hline & \multicolumn{3}{|l|}{ ATIVIDADES EXTRAS } \\
\hline & \multicolumn{3}{|l|}{ RESPONSABILIDADES EM CASA } \\
\hline & \multicolumn{3}{|l|}{ ENTRETENIMENTO / TEMPO LIVRE } \\
\hline \multirow[t]{3}{*}{$\begin{array}{l}\text { BRINCAR / } \\
\text { BRINCADEIRAS }\end{array}$} & \multicolumn{3}{|c|}{$\begin{array}{l}\text { EU DESÇO (descer para a área comum do condomínio / social) - jogar bola, encontrar com amigos, } \\
\text { parquinho, nadar, caminhar, quadra de areia, sala de jogos. }\end{array}$} \\
\hline & \multicolumn{3}{|l|}{ JOGOS DE COMPUTADOR } \\
\hline & VIDEOS DE YOUTUBE & \multicolumn{2}{|c|}{$\begin{array}{l}\text { BLOGUEIRA, INTERCÂMBIO, DICAS, VLOG, JOGOS } \\
\text { (Minecraft), ARTESANATO, DIY (Do it yourself- faça } \\
\text { você mesmo -aprendendo com os youtubers, YOUTUBER } \\
\text { = AMIGA (proximidade emocional) }\end{array}$} \\
\hline \multirow{2}{*}{$\begin{array}{l}\text { O LOCAL E O } \\
\text { GLOBAL }\end{array}$} & \multicolumn{3}{|c|}{ O VELHO DO SACO (cultura do condomínio) } \\
\hline & \multicolumn{3}{|c|}{ BRINCADEIRAS TRADICIONAIS / BONECA (cultura da infância) } \\
\hline \multirow{12}{*}{$\begin{array}{l}\text { TECNOLOGIA / } \\
\text { INTERNET }\end{array}$} & \multicolumn{3}{|l|}{ TODOS OS DIAS (HÁBITO) } \\
\hline & \multicolumn{3}{|c|}{ CASTIGO (Relação com os pais) - CASA/ESCOLA } \\
\hline & \multicolumn{3}{|c|}{$\begin{array}{l}\text { COMUNICAÇÃO } \\
\text { "falar com pessoas que você conhece, é lógico" IMEDIATA (pais) } \\
\text { PESSOAS QUE ESTÃO LONGE }\end{array}$} \\
\hline & \multirow[t]{2}{*}{ ACESSO A BENS CULTURAIS } & \multicolumn{2}{|c|}{$\begin{array}{l}\text { ACESSO A CONHECIMENTO } \\
\text { "saber tudo na vida, no universo" }\end{array}$} \\
\hline & & \multicolumn{2}{|c|}{$\begin{array}{l}\text { ACESSO A ENTRETENIMENTO - FÁCIL/FLEXÍVEL } \\
\text { (episódio da novela que perdeu) }\end{array}$} \\
\hline & \multirow{4}{*}{$\begin{array}{l}\text { MAIS QUE UM INSTRUMENTO - } \\
\text { ESPAÇO DE ATUAÇÃO DO SER } \\
\text { HUMANO } \\
\text { IMPACTO NAS RELAÇÕES }\end{array}$} & \multicolumn{2}{|c|}{ FAZER COISA BOA / FAZER COISA RUIM } \\
\hline & & \multicolumn{2}{|c|}{$\begin{array}{l}\text { PRA DEIXAR AS MÃES PREOCUPADAS "porque tem } \\
\text { muita coisa RUIM NA INTERNET" }\end{array}$} \\
\hline & & \multicolumn{2}{|c|}{ FICAR DE CASTIGO } \\
\hline & & \multicolumn{2}{|c|}{ FAZER TRABALHO EM GRUPO } \\
\hline & \multirow{2}{*}{ LUGAR DE ENCONTRO } & \multicolumn{2}{|c|}{ TIRAR NOTA BOA NO TRABALHO } \\
\hline & & \multirow{2}{*}{\multicolumn{2}{|c|}{$\begin{array}{l}\text { HÁBITO } \\
\text { MUITO DIFÍCIL VIVER SEM - "ser humano do século } \\
\text { XXI e dos séculos para frente" }\end{array}$}} \\
\hline & $\begin{array}{l}\text { LUGAR DE SUBJETIVAÇÃO E } \\
\text { AÇÃO }\end{array}$ & & \\
\hline $\begin{array}{l}\text { TECNOLOGIA } \\
\text { /INTERNET }\end{array}$ & \multicolumn{3}{|c|}{ TEMPORALIDADE "perdi um dia inteiro" } \\
\hline \multirow{4}{*}{$\begin{array}{l}\text { MUNDO SEM } \\
\text { TECNOLOGIA }\end{array}$} & \multirow{4}{*}{\multicolumn{2}{|c|}{$\begin{array}{l}\text { CELULAR - CONDIÇÃO PARA A VIDA } \\
\text { VIDA X MORTE } \\
\text { Pensar sobre outros objetos que encapsularam } \\
\text { essa metáfora. } \\
\text { B narra uma história pessoal a partir dessa } \\
\text { afirmação de M. }\end{array}$}} & SE NEGA A VIVER SEM \\
\hline & & & VOLTA ȦS CAVERNAS \\
\hline & & & $\begin{array}{l}\text { ZUMBI- "andar pra lá, pra cá"- "bater com a cara } \\
\text { na parede" }\end{array}$ \\
\hline & & & BOM E RUIM AO MESMO TEMPO \\
\hline $\begin{array}{l}\text { TECNOLOGIA } \\
\text { /INTERNET }\end{array}$ & \multicolumn{2}{|l|}{ TENTAÇÃO } & CELULAR - LEGAL "eu vou ficar lendo papel?" \\
\hline $\begin{array}{l}\text { TECNOLOGIA } \\
\text { /INTERNET }\end{array}$ & \multicolumn{2}{|l|}{ VÍCIO } & $\begin{array}{l}\text { TV/CELULAR } \\
\text { CONSUMIR O TEMPO }\end{array}$ \\
\hline
\end{tabular}

Fonte: Elaborada por Krüger-Fernandes, 2018 
Desenhando o mapa semiótico a partir da tabela de temas

Tomando como ponto de partida a tabela cronológica de temas e subtemas, elaborou-se o mapa semiótico. No caso da pesquisa aqui apresentada, optou-se pela utilização de um software de uso livre chamado Xmind- versão 7.5 -, o qual é descrito pelos criadores como: “[...] um software de mapeamento mental e brainstorming, desenvolvido pela XMindLtd". A partir da análise dos enunciados e dos blocos de diálogo, os temas e subtemas emergentes foram identificados, assim como suas relações e contraposições, como pode ser visto na Figura 2.

Figura 2. Mapa semiótico organizado a partir da tabela de organização de temas em ordem cronológica. *Utilização do software Xmind.

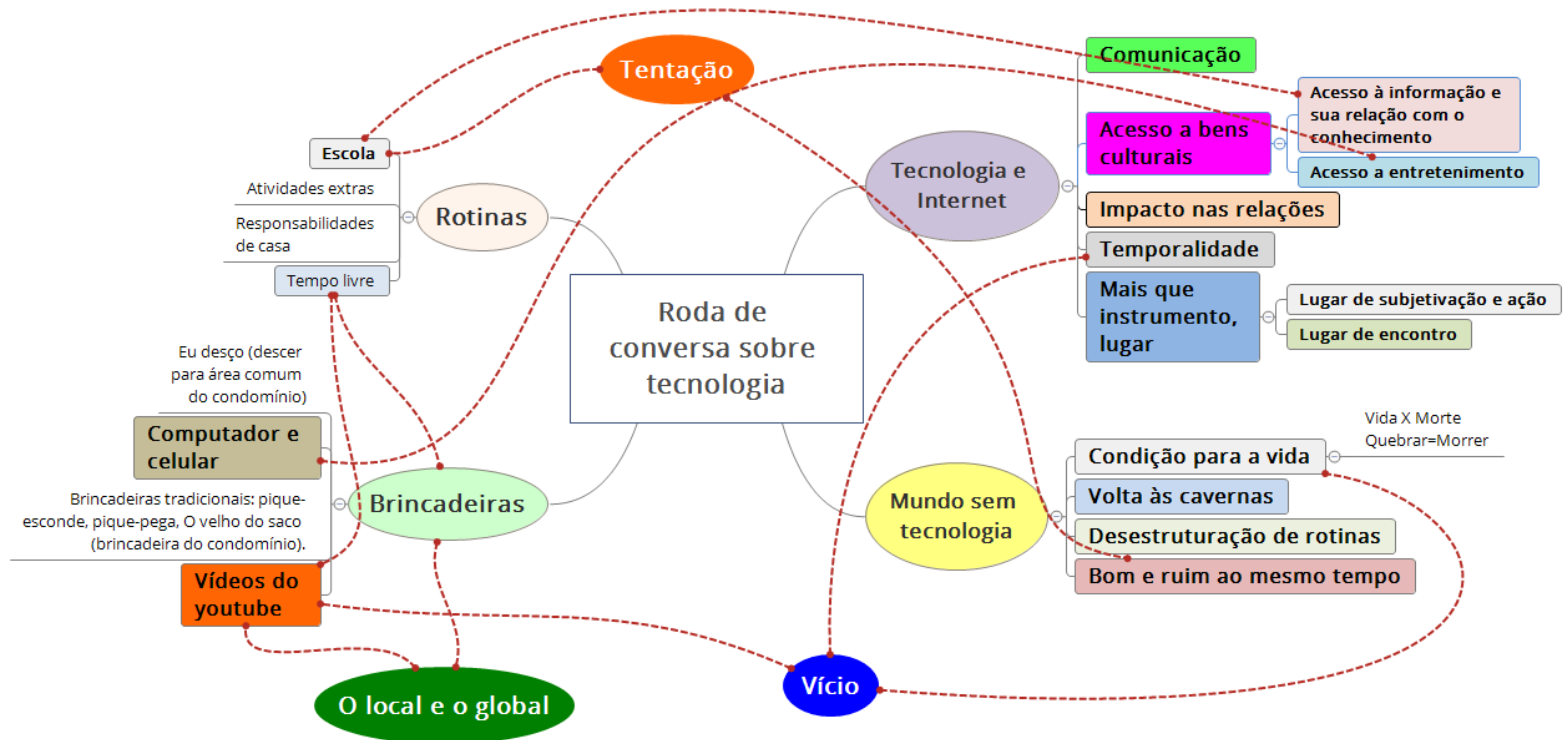

Legenda:
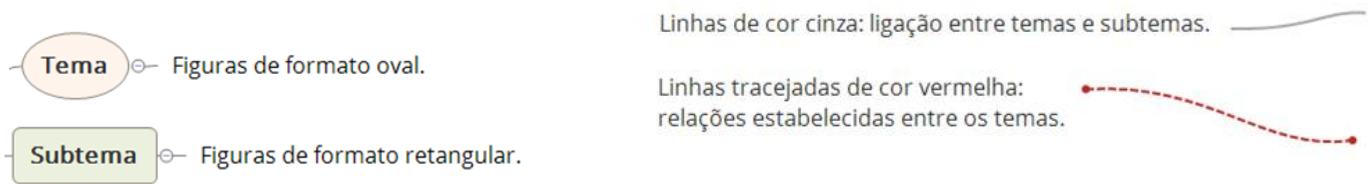

Fonte: Elaborada por Krüger-Fernandes, 2018

Foram identificados quatro temas principais localizados no mapa em figuras de formato oval: (1) Rotinas, (2) Brincadeiras, (3) Tecnologia e Internet e (4) Mundo sem tecnologia. Os subtemas aparecem ligados a esses temas principais por linhas de cor cinza indicando a relação entre eles nas falas das crianças. Com o objetivo de salientar os subtemas ligados aos temas Tecnologia e Internet e Mundo sem tecnologia utilizamos figuras de formato retangular e cores diferentes para melhor visualização e diferenciação. Os temas Tentação e Vicio foram adicionados ao mapa em espaços independentes, pois perpassaram a conversa e se relacionaram de maneira relevante com 
vários temas e subtemas. O mesmo aconteceu com o tema $O$ local e o global. Essas relações podem ser identificadas pelas linhas vermelhas tracejadas que ligam temas e subtemas.

\section{Análise do mapa semiótico}

Analisando o mapa, podemos notar a ligação do tema Rotinas com os subtemas Escola, Atividades Extras, Responsabilidades de Casa e Tempo Livre, indicando que esses fatores orientam as rotinas das crianças. A relação entre os subtemas Escola e Acesso à informação e sua relação com o conbecimento - o qual se encontra ligado ao tema mais amplo Tecnologia e Internet - indica a percepção das crianças sobre a presença das tecnologias em suas vidas nesse momento de aprendizagem institucionalizado. Ainda relacionado ao subtema Escola, podemos ver a ideia de Tentação, que as crianças atribuem às tecnologias em momentos de estudo. Para elas, smartphones e tablets trazem significados ambíguos para esses momentos, pois, apesar de serem necessários para a realização de suas atividades escolares, também funcionam como distrações por seu acesso ao entretenimento e a consequente relação com momentos de lazer. Portanto, as crianças expressaram que um mundo sem tecnologia seria bom e ruim ao mesmo tempo, pois não teriam de lidar com essa ambiguidade nem com o gerenciamento entre responsabilidades escolares e momentos de lazer mediados pela tecnologia.

Relacionado ao tema Brincadeiras, encontramos o subtema Tempo livre, o qual se relaciona, por sua vez, ao subtema Videos do youtube, indicando o entendimento das crianças de que a atividade de assistir aos vídeos no youtube se configura como uma forma de brincar, compondo seus momentos de brincadeira. Esse fato se relaciona com o entrecruzamento de culturas locais e globais nos momentos de brincadeira das crianças, o que explica a relação estabelecida pela linha tracejada entre o tema Brincadeiras e a figura O local e o global e entre este e o subtema Videos do youtube. Mais além, o subtema Computador e celular, ligado ao tema Brincadeiras, indica a presença dessas tecnologias no momento de brincadeiras das crianças como meios de acesso a jogos e vídeos, e que, por isso, se relaciona com o subtema Acesso a entretenimento, o qual está ligado ao tema mais amplo Tecnologia e Internet.

Também ligados ao tema Tecnologia e Internet, podemos encontrar os subtemas Comunicação e Acesso a bens culturais, que indicam funções que as tecnologias e a internet assumem na vida das crianças, possibilitando que elas se comuniquem com pais e colegas e que acessem conteúdos relacionados à construção de conhecimento e atividades escolares, assim como conteúdos de entretenimento. A noção expressa pelas crianças de que as tecnologias influenciam em suas relações, principalmente com os pais, está indicada pelo subtema Impacto nas relações. Já o subtema Mais que instrumento, lugar, indica o entendimento de que a internet se configura como espaço de relação com os outros e de subjetivação e ação, estando sujeito a implicações éticas e morais. Ressaltamos que as crianças utilizaram os termos tecnologia e internet como sinônimos ao longo da roda de conversa, sendo esse o motivo da associação dos dois termos no tema Tecnologia e Internet.

O subtema Vídeos do youtube se relaciona também com a noção de Vicio, demonstrando a sensação que as crianças têm de estarem viciadas na atividade de assistir a vídeos no youtube. Essa noção também se relaciona com o subtema Temporalidade, indicando a forma com que as crianças percebem a vivência do tempo em relação às novas tecnologias. Por fim, a mesma ideia de Vício se relaciona com o subtema Condição para a vida, expressando o entendimento das crianças de que as novas tecnologias se constituem como condição para a vida, de tal forma que o fato de o celular quebrar levaria à morte da pessoa, o que é explicado pelo vício. Esse subtema encontra-se ligado ao tema mais amplo Mundo sem tecnologia, assim como os subtemas Volta às cavernas, 
Desestruturação de rotinas e Bom e ruim ao mesmo tempo indicando uma sequência gradativa em que a tecnologia é entendida em um primeiro momento como imprescindível e desestruturante, para logo mais ser compreendida a partir de seus prós e contras.

Na próxima seção, trataremos da emergência do tema Mundo sem tecnologia, apresentando os diálogos empreendidos pelas crianças, assim como a análise empreendida em relação a esses diálogos. Sabemos que os temas e subtemas aparecem nas falas das crianças de maneira relacionada, por isso, apesar de termos evidenciado o tema como tópico, trataremos também dos subtemas relacionados a esse tema.

\section{Análise dos enunciados em diálogo: a emergência do tema Mundo sem tecnologia}

Em certo momento da roda de conversa, o diálogo das crianças se organizou em torno do tema Mundo sem tecnologia, o qual se caracterizou por um exercício hipotético que demandou recursos imaginativos sobre como seria a vida sem tecnologia. Pode-se observar que, nesse momento, as reações e as falas das crianças obedeceram a uma sequência gradativa, em que a tecnologia é considerada como condição essencial para vida em um primeiro momento até a relativização dessa condição trazendo pontos positivos e negativos, como pode ser observado no mapa semiótico exposto na Figura 2.

Identificamos a emergência do tema Mundo sem tecnologia com uma fala da participante Mar em que ela expressa a noção de que o celular se configura como condição essencial para a vida. Após pedir a palavra, Mar diz: "[...] por exemplo... o seu celular quebra, ou seja, ele morre... aí a pessoa morre junto. Por quê? Porque tá tão viciada no celular que se ele quebrar, ela quebra junto". Podemos depreender da fala da participante que ela justifica a relação de dependência entre a vida e o celular pelo vício, uma questão já levantada pelas crianças em outros momentos da roda de conversa e que se refere à sensação de estar viciado no uso do celular, mais especificamente do smartphone. Além disso, ao analisar o posicionamento de Mar e seu processo de argumentação, podemos observar as pausas ao longo da fala da participante e a utilização das conjunções interrogativa e causal (por quê e porque), as quais refletem um raciocínio exteriorizado que se faz na expressão verbal, demonstrando o caráter reflexivo e dialógico da roda de conversa como procedimento metodológico de pesquisa (RIBEIRO; KRÜGERFERNANDES; BORGES, 2020; PONTECORVO; AJELLO; ZUCCHERMAGLIO, 2005).

A pesquisadora, ao ouvir Mar, nota a potencialidade de sua expressão como ponto de abertura para novas discussões e chama a atenção dos outros participantes, validando a fala de Mar e dando espaço para que a participante emita novamente sua opinião. Compreendemos que, nesse caso, o direcionamento da pesquisadora atuou de forma a potencializar o enunciado de Mar e ampliar seus interlocutores, como pode ser visto na resposta de Bela que se apoia na fala de Mar para produzir seu posicionamento baseado em uma experiência pessoal.

P- Mar, quer falar?

M- Sim, por exemplo, o seu celular quebra, ou seja, ele morre. Aí a pessoa morre junto. Por quê? Porque tá tão viciada no celular que se ele quebrar, ela quebra junto.

P- É mesmo? Vocês ouviram isso aqui que a Mar falou? Que quando o celular morre, né...

M- É, ou seja, ele quebra...aí ele acaba morrendo... ele quebrou... é... o ser humano morre também.

P- O ser humano morre também? 
DOI: $10.12957 /$ teias. $\%$ Y.50727

B- Aaai, eu tenho uma experiência disso muito triste. Foi no ano passado isso, eu acho...eu..éee... a minha tia...foi a primeira vez que eu ganhei um I-phone e eu não cuido muito bem das coisas. E aí, eu já tinha quebrado esse celular uma vez. E aí todo mundo ficou assim: Bela, num dá, né..Bela, num dá..e eu: desculpa, desculpa. Eu fiz o meu pai consertar o celular de novo. Aí meu pai consertou o celular. Aí eu fui e quebrei o celular de novo. Aí eu fiquei 7 meses sem celular...e eu fiquei muito triste naquela época.

Bela, partindo da fala de Mar, se identifica com a situação descrita pela colega e inicia uma narrativa em que ela traz uma experiência pessoal com o objetivo de exemplificar e responder ao enunciado de Mar. Utilizando-se da memória para reconstituir uma experiência passada no presente, Bela retoma um evento que parece ser reconhecido como importante em sua vida: "a primeira vez que eu ganhei um I-phone" (BRUNER, 1997). Ao narrar o acontecimento de ter quebrado o celular duas vezes, Bela traz em sua narrativa as vozes de outras pessoas e sua própria voz realocada nesse tempo passado, como podemos ver no trecho: "e aí todo mundo ficou assim: Bela, num dá, né..Bela, num dá..e eu: desculpa, desculpa...”. Ela caracteriza esse evento como uma experiência triste causada pela falta do celular, o que converge com a fala de Mar. Desse modo, o posicionamento de Bela em relação à fala de Mar se trata de um espaço de construção coletiva em que os dizeres de ambas dialogam responsivamente pelos processos de alteridade, em que a palavra é, de certa maneira, um elo constitutivo na fronteira no e do discurso alheio (PONZIO, 2012).

Partindo da fala da participante Mar, a pesquisadora se aproxima do tema e lança uma pergunta a todos os participantes com o objetivo de entender melhor como as crianças percebem a tecnologia em suas vidas, colocando o tema em outra perspectiva, o da falta do recurso. $\mathrm{O}$ diálogo se desenrolou desta forma:

(1)P- Então, vocês adivinharam minha próxima pergunta. Porque a minha próxima pergunta é... vocês já imaginaram algum dia assim um mundo sem tecnologia?

(2)U- Eu já.

(3)P- Como é que ia ser?

(4)B- Já passei por essa experiência. Não quero.

*Unicórnio pula do sofá e se agacha no meio dos outros participantes com os punhos fechados em frente ao peito.

(5)U- Uga-uga, uga-uga.

(6)P- Ia ser Uga-uga sem tecnologia. Se a gente não tivesse mais celular, que mais, deixa eu ver, carro, né, que mais... TV

(7)U- A gente ia ser tudo assim... ia andar pra lá, pra cá, pra lá, pra cá.

(8)M- Eu morro sem TV.

(9)P- Como é que ia ser nossa vida?

(10)U- Ia ser andando.

(11)M- Eu ia ficar assim, ó...

* Mar se levanta do sofá e anda espaços curtos de um lado para o outro demonstrando sua fala.

(12)P- Zumbi.

(13)M- Batendo com a cara na parede.

Os posicionamentos em relação à pergunta da pesquisadora se dão de maneira rápida e espontânea. Unicórnio diz já ter imaginado o mundo sem tecnologia, ao passo que Bela se remete 
à experiência em que relatou ter ficado sete meses sem o celular, dizendo "Já passei por essa experiência. Não quero.”. Logo após a fala de Bela, Unicórnio pula do sofá e se agacha no meio dos outros participantes com os punhos fechados em frente ao peito emitindo os sons: "Uga-uga, uga-uga". Nessa fala performática de Unicórnio - turno 5 - fica evidente a relação que essa participante faz entre a falta de tecnologia e uma volta a condições primitivas de vida. Ao pular do sofá para o chão com os punhos fechados em frente ao peito emitindo os sons "uga-uga" repetidamente, Unicórnio parece se referir a representações convencionadas da época em que os seres humanos viviam em cavernas.

No turno 11, percebe-se que Mar responde à fala de Unicórnio e demonstra corporalmente como seria a vida sem tecnologia. Da expressão das duas participantes, pode-se depreender que a vida sem tecnologia desestrutura as rotinas já estabelecidas em nossa sociedade que são dependentes das tecnologias da informação e comunicação (CASTELLS, 2016) e da virtualização desses processos (LÉVY, 1996), ocasionando um momento de crise que se revela nos movimentos erráticos de Mar e em sua fala: "Batendo com a cara na parede". As reações corporais de Unicórnio e Mar são carregadas de significados e se encontram indissociáveis de suas falas, e é a partir dessas expressões que os subtemas relacionados ao tema Mundo sem tecnologia vão se definindo, a saber: Volta às cavernas e Desestruturação de rotinas. Nota-se que os elementos extraverbais que se fazem presentes nesse diálogo são imprescindíveis para a identificação dos subtemas e para o empreendimento da análise (VOLÓCHINOV, 2017).

Por fim, Bela, após ouvir suas colegas, pondera aspectos positivos e negativos da falta da tecnologia, que, neste caso, é entendida exclusivamente por sua ligação com a internet. Ela traz movimentos contraditórios em sua fala, característicos do processo dialógico, como se pode ler no próximo trecho:

B- Na minha opinião...eu acho que... se a gente não...se a gente não tivesse internet... tipo... ao mesmo tempo que seriiiaaa ruim, seria bom... porque assim, por exemplo... às vezes eu fico muuito triste com o dever. Aí eu vou atrás do meu celular...é como se fosse uma tentação, né. Porque você fica...ahh, tá tão legal mexer no celular, eu vou ficar lendo papel? Vou ficar fazendo as coisas? [...] E eu acho que assim... talvez..talvez... eu acho que seria muito chato...porque eu adoooro tecnologia... essas coisas assim, mas eu acho que talvez não seria tão ruim assim se a gente não conhecesse.

Bela expressa o prazer sentido na interação com o celular que aparece como uma compensação para momentos em que ela se sente triste com suas obrigações escolares e logo faz uma comparação entre a experiência de interagir com o celular e a experiência de interação com "papel". A primeira se mostra como uma experiência de prazer, que parece estar relacionada com a interatividade possível pelo celular, ou então aos conteúdos que ela acessa por meio dele. Já a experiência de interação com o papel parece relacionar-se a suas obrigações escolares e tarefas de casa. Para ela, o lado bom de não ter internet se mostra como a não-existência de uma tentação que a faz desviar sua atenção de suas obrigações escolares. Essa contradição sentida por Bela faz parte de um contexto cultural mais amplo da infância urbana em que as crianças têm de aprender a gerenciar seu tempo entre as obrigações escolares e os momentos de lazer, muitas vezes mediados pelas tecnologias (KRÜGER-FERNANDES; BORGES, 2020; MARTINS; CASTRO, 2011). No entanto, após pesar os lados bom e ruim da vida sem internet, ela adiciona: "eu acho que seria muito chato. Porque eu adoooro tecnologia.", ressaltando sua ligação afetiva com os aparelhos digitais móveis. 
Pode-se compreender por meio do exemplo descrito que os elementos extraverbais que compõem a situação concreta de enunciação foram imprescindíveis para a definição do tema e dos subtemas que se encontram indicados no mapa semiótico exposto na Figura 2. Foi dessa maneira que a pesquisadora pôde identificar o tema Mundo sem tecnologia e os subtemas Condição para a vida, Volta às cavernas e Desestruturação de Rotinas a partir da situação vivida com os participantes. Além disso, a consideração dos pressupostos que embasam a Análise Temática Dialógica permitiu uma análise mais detalhada tanto das situações concretas de enunciação como também do mapa semiótico elaborado a partir delas.

\section{CONCLUSÕES}

Este artigo teve como objetivo apresentar a Análise Temática Dialógica, seus fundamentos epistemológicos e sua aplicação em um contexto de pesquisa qualitativa que se utilizou de roda de conversa como procedimento metodológico. Ao tratar do processo de interação dialógica que ocorre em uma roda de conversa, a Análise Temática Dialógica nos permite uma aproximação das informações construídas com os participantes que leva em consideração aspectos relevantes relacionados ao funcionamento da língua, os quais se encontram expressos nos pressupostos da análise, tais como: o caráter dialógico da língua, o entendimento da palavra como signo ideológico, a concepção de tema, assim como os conceitos de endereçamento e alteridade. Partindo desses pressupostos como orientadores da análise, o processo se inicia com a transcrição do material (audiogravado ou videogravado), seguido de leitura intensiva com o foco no encadeamento dos enunciados e organização dos enunciados em temas e subtemas, culminando na elaboração e análise dos mapas semióticos.

A organização dos temas e subtemas no mapa semiótico permite identificar de maneira clara como evoluiu a roda de conversa, assim como os temas e subtemas que tiveram maior relevância para as crianças. No caso da pesquisa aqui apresentada, a roda de conversa se organizou em torno dos temas: Rotinas, Brincadeira, Tecnologia e Internet, Mundo sem tecnologia, Tentação e Vicio. Esses temas se relacionaram entre eles e com os subtemas, indicando o lugar que as tecnologias ocupam nas vidas das crianças. Além disso, a concepção de tema que orienta a Análise Temática Dialógica nos conduz a ter um olhar atento para os enunciados performáticos das crianças, que englobam movimentos corporais expressivos carregados de significados. Considerar esses elementos extraverbais como parte constitutiva do tema contribuiu para nossa compreensão de como essas crianças se sentiriam em um mundo sem tecnologia, entre outros pontos.

Consideramos que a Análise Temática Dialógica, como proposta metodológica de análise em uma perspectiva qualitativa, se apresenta como um procedimento profícuo para refletir sobre as informações produzidas em processo de interação dialógica de roda de conversa com crianças. A aproximação do material audiovisual (de videogravação) e do material transcrito conduzida por um olhar minucioso que prioriza o endereçamento e o encadeamento dos enunciados produzidos na interação, a organização das falas em temas e subtemas e a construção dos mapas semióticos contribuem de forma relevante para o processo de análise, principalmente por possibilitar interpretações dos diálogos entre os participantes e com a pesquisadora pelo desenvolvimento de processos múltiplos de linguagem e alteridade. Acreditamos que esse trabalho possa contribuir para as discussões sobre métodos de análise em pesquisa qualitativa, principalmente em pesquisas com crianças que tenham um enfoque dialógico. 


\section{REFERÊNCIAS}

AMORIM, Marília. Vozes e silêncio no texto de pesquisa em Ciências Humanas. Cadernos de Pesquisa, São Paulo, n. 116, p. 07-19, jul. 2002. Disponível em https://doi.org/10.1590/S010015742002000200001. Acesso em 22 ago. 2020.

AMORIM, Marília. Cronotopo e exotopia. In: BRAIT, Beth (org.). Bakhtin: Outros conceitos-chave. São Paulo: Contexto, 2012, p. 95-114.

BAKHTIN, Mikhail. O freudismo: esboço crítico. Rio de Janeiro: Editora Perspectiva, 2001.

BAKHTIN, Mikhail. Estética da criação verbal. São Paulo: Martins Fontes, 2011.

BERALDO, Rossana Mary Fujarra. Dinâmicas de intersubjetividade em atividades colaborativas em contexto mediado por fórum online no ensino médio. 208 f. Tese (Doutorado em Processos de Desenvolvimento Humano e Saúde), Universidade de Brasília, Brasília, 2017.

BORGES, Fabrícia Teixeira. "Tem tantos jeitos de ver!" Um estudo sobre os significados de olhar nas perspectivas de quatro mulheres de Goiania. 2006. 235 f. Tese (Doutorado em Psicologia), Universidade de Brasília, Brasília, 2006.

BRUNER, Jerome. Atos de significação. Porto Alegre: Artes Médicas, 1997.

CAIXETA, Juliana Eugênia. Guardiãs da memória: tecendo significações de si, suas fotografias e seus objetos. 224 f. Tese (Doutorado em Psicologia), Universidade de Brasília, Brasília, 2006.

CASTELLS, Manuel. A sociedade em rede. São Paulo: Paz e Terra, 2016.

CEREJA, William. Significação e tema. In: BRAIT, Beth (org.). Bakbtin: Conceitos-chave. São Paulo: Contexto, 2005, p. 201-220.

KRÜGER-FERNANDES, Larissa. Infância urbana e novas tecnologias: uma análise pela perspectiva da criança. 2018. 142 f. Dissertação (Mestrado em Processos de Desenvolvimento Humano e Saúde), Universidade de Brasília, Brasília, 2018.

KRÜGER-FERNANDES, Larissa; BORGES, Fabrícia Teixeira. Infâncias urbanas e tecnologias digitais: Reflexões a partir de uma roda de conversa com crianças. In: VERSUTI, Andrea; MIER, Catalina; SANTINELLO, Jamile (org). Comunicação, Educação e a Construção do Conhecimento, Aveiro: Ria Editorial, 2020, p. 154-175. Disponível em http://www.riaeditorial.com/index.php/comunicacao-educacao-e-a-construcao-doconhecimento/. Acesso em 28 ago 2020.

LÉVY, Pierre. O que é o virtual? São Paulo: Editora 34, 1996.

MARTINS, Luana Timbó; CASTRO, Lucia. Crianças na contemporaneidade: Entre as demandas da vida escolar e da sociedade tecnológica. Revista Latinoamericana de Ciencias Sociales, Niñez y Juventud, v. 2, n. 9, p. 619-634, 2011.

NAVES, Renata Magalhães. Experiência estética e posicionamento ético: a arte com crianças e adolescentes em vulnerabilidade social. 194 f. Tese (Doutorado em Processos de Desenvolvimento Humano e Saúde), Universidade de Brasília, Brasília, 2019.

PAIXÃO, Gleice Aline Miranda da. A imaginação e seu lugar no currículo, nas narrativas e na prática docente. 204 f. Tese (Doutorado em Processos de Desenvolvimento Humano e Saúde), Universidade de Brasília, Brasília, 2020.

PONTECORVO, Clotilde; AJELLO, Anna Maria; ZUCCHERMAGLIO, Cristina. Discutindo se aprende. Porto Alegre: Artmed, 2005. 
PONZIO, Afonso. A revolução bakbtiniana. São Paulo: Editora Contexto, 2012.

RIBEIRO, Lady Daiane; KRÜGER-FERNANDES, Larissa; BORGES, Fabrícia Teixeira. Roda de conversa mediada por leitura dialógica com crianças: uma proposta metodológica de pesquisa qualitativa sobre processos argumentativos. In: OLIVEIRA E SÁ et al (org.). Investigação qualitativa em educaşão: avanços e desafios, Lisboa: Ludomedia, 2020, p. 83-95. Disponível em https://doi.org/10.36367/ntqr.2.2020.83-95 84. Acesso em 24 ago. 2020.

SILVA, Cátia Cândido; BORGES, Fabrícia Teixeira. Análise Temática Dialógica como método de análise de dados verbais em pesquisas qualitativas. Linhas Críticas, v. 23, p. 245-267, 2017.

VALSINER, Jaan; ROSA, Alberto. The Cambridge Handbook of social-cultural psychology. New York: Cambridge University Press, 2007.

VIGOTSKI, Lev. A formação social da mente. São Paulo: Martins Fontes, 2010.

VIGOTSKI, Lev; LURIA, Alexander; LEONTIEV, Alexei. Linguagem, Desenvolvimento e Aprendizagem. São Paulo: Ícone/EDUSP, 2016.

VYGOTSKI, Lev. Obras escogidas - II: Pensamiento y lenguaje, Conferencias sobre psicología. Espanha: Antonio Machado, 2014.

VOLÓCHINOV, Valentin. Marxismo e filosofia da linguagem. São Paulo: Editora 34, 2017.

WERTSCH, James. The primacy of mediated action in sociocultural studies. Mind, Culture, and Activity, n. 1:4, p. 202-208, 1994. DOI: 10.1080/10749039409524672

\section{Informações das autoras}

Larissa Krüger-Fernandes

Universidade de Brasília

E-mail: larissakf54@gmail.com

ORCID: http://orcid.org/0000-0003-3817-0016

Link Lattes: http://lattes.cnpq.br/4558190341865823

Lady Daiane Martins Ribeiro

Universidade de Brasília

E-mail: ladyfsp@gmail.com

ORCID: https://orcid.org/0000-0001-8922-3638

Link Lattes: http://lattes.cnpq.br/5517876040149128

Fabrícia Teixeira Borges

Universidade de Brasília

E-mail: fabricia.borges@gmail.com

ORCID: http://orcid.org/0000-0002-9341-2738

Link Lattes: http://lattes.cnpq.br/5263796882373579 